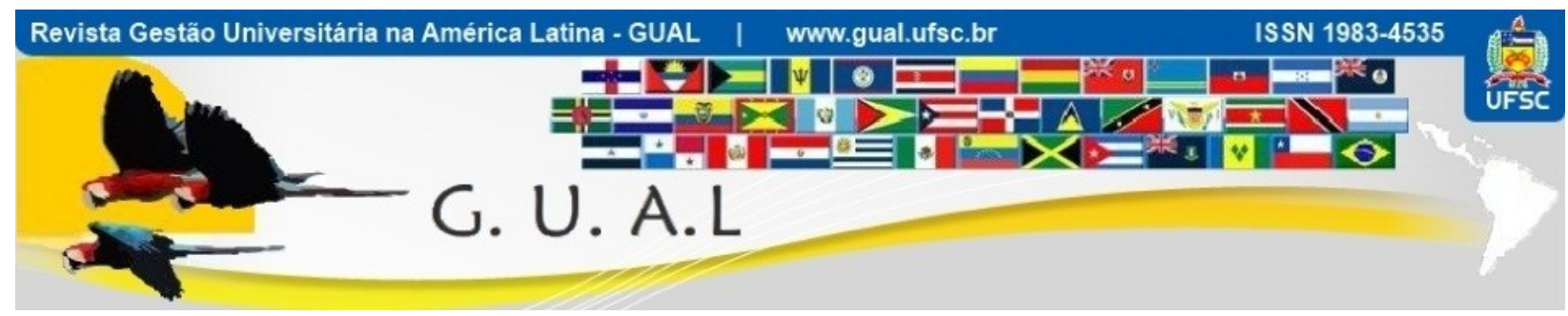

DOI: http://dx.doi.org/10.5007/1983-4535.2012v5n3p287

\title{
APRENDENDO ADMINISTRAÇÃO EM LABORATÓRIO: DESAFIOS E FRUSTRAÇÕES DE UMA EXPERIÊNCIA
}

\author{
LEARNING MANAGEMENT IN LABORATORY: CHALLENGES AND \\ FRUSTRATIONS FROM AN EXPERIENCE
}

Jorge Alberto dos Santos, Doutor Universidade Federal de Viçosa - UFV jalberto@ufv.br

Simone Martins, Mestre Universidade Federal de Viçosa - UFV simone.m@ufv.br

Recebido em 02/agosto/2012

Aprovado em 17/outubro/2012

Sistema de Avaliação: Double Blind Review

Esta obra está sob uma Licença Creative Commons Atribuição-Uso. 


\title{
RESUMO
}

O objetivo deste artigo é relatar a experiência de concepção e implantação de um projeto que aqui chamaremos de Laboratório de Práticas Organizacionais (LPO) no Departamento de Administração e Contabilidade de uma Instituição Federal de Ensino Superior. Nós, os professores idealizadores do projeto, o definimos como um espaço físico e conceitual holístico para a aprendizagem e treinamento de princípios e práticas administrativas e gerenciais nos três níveis de uma organização: operacional, tático e estratégico. Apoiamos nosso projeto na visão construtivista de aprendizado e no desenvolvimento de pesquisas que mostram a necessidade de repensar epistemologicamente o ensino-aprendizagem em administração, tais como os resultados surgidos da pesquisa do ETL Project (Enhancing Teaching-Learning Environments in Undergraduate Courses), (HOUNSELL e ENTWISTLE, 2005). Consideramos que o projeto enfrentou diversos desafios e que alguns de nossos sonhos foram ofuscados, tornando-se frustrações. A principal conclusão de nosso trabalho é que há espaço na Universidade para inovações do tipo que propusemos, desde que estejamos dispostos a enfrentar os desafios e as frustrações inerentes a iniciativas não convencionais de ensino-aprendizagem.

Palavras-chave: Ensino de administração. Aprendizagem experiencial. Aprender fazendo.

\begin{abstract}
In this paper, we describe and reflect on the experience of the authors in setting up a new model of learning environment in management education in a Brazilian University. The learning environment would allow students to practise management skills in a setting called Management Practice Laboratory (MPL). The MPL environment was conceived as a physical and conceptual space where students could learn and practise the principles and techniques of working in organisations in their three levels: operational, tactical, and strategic. The foundations of our project come from the social constructivist perspective on learning, experiential learning literature, and research studies (HOUNSELL e ENTWISTLE, 2005) that call for a new epistemological ground in learning. Despite the challenges and frustrations, we conclude that once one shows courage to overcome the challenges and frustrations, there is room for innovation in the way one teaches and learns about management in Universities.
\end{abstract}

Keywords: Management learning. Experiential learning. Learn by doing. 


\section{APRENDENDO ADMINISTRAÇÃO EM LABORATÓRIO: DESAFIOS E FRUSTRAÇÕES DE UMA EXPERIÊNCIA \\ DOI: http://dx.doi.org/10.5007/1983-4535.2012v5n3p287}

\section{INTRODUÇÃO}

Este artigo apresenta o relato da experiência de dois professores do Departamento de Administração e Contabilidade de uma Instituição Federal de Ensino Superior na concepção e implantação de um projeto que chamaremos aqui de Laboratório de Práticas Organizacionais (LPO). A concepção do modelo - como será explicado em detalhes mais a frente pressupunha a construção de dois "ambientes": a) um ambiente físico que chamaremos de Laboratório Organizacional, constituído de um conjunto de equipamentos materiais e tecnologias de escritório e; b) um ambiente conceitual que chamaremos de "país ou mundo paralelo", constituído de um conjunto de leis e normas criadas para "simular" um país fíctício ao qual daremos o nome de Simulândia. Desta forma, o LPO será definido como um espaço físico e conceitual holístico para a aprendizagem e treinamento de princípios e práticas de trabalho em organizações em seus três níveis: o nível operacional, o tático e o estratégico. Tal ambiente de aprendizagem proporcionaria ao estudante uma formação tanto no aspecto técnico-funcional das organizações quanto no aspecto comportamental-social do trabalho em equipes.

Desta forma, a estrutura física representaria a infra-estrutura tecnológica para a operacionalização de um micro ambiente social planejado, que possibilitasse a organização de "atividades andragógicas" - atividades que fossem representativas da realidade, embora reduzidas em complexidade. No sentido de espaço físico, o projeto foi entendido não só como um "local" onde ocorre uma experiência de aprendizagem (WILSON, 1996; ILLERIS, 2002), mas também e mais apropriadamente como "uma pré-condição de todas as nossas práticas e engajamentos... para a construção do relacionamento entre as pessoas..."i (MASSEY, 2004, p.1). Orientadas por professores, estas práticas permitiriam aos estudantes vivenciarem o diaa-dia de uma organização, discutirem os seus problemas, proporem soluções e treinarem as habilidades necessárias à sua condução. Concomitantemente, tal estrutura permitiria aos professores conduzirem pesquisas sobre as dinâmicas de aprendizado, em uma abordagem que a teoria em pesquisa educacional vem denominando atualmente de "design-based research" (COLLINS, 1992; BARAB e SQUIRE, 2004).

O projeto foi desenvolvido de acordo com a crença de que o ensino-aprendizagem em administração apresenta uma epistemologia própria e que esta epistemologia ainda é desconhecida ou desconsiderada pela maioria dos docentes em administração. Desta forma, estes se apoiam, consciente ou inconscientemente, em uma epistemologia derivada do ensino 


\section{APRENDENDO ADMINISTRAÇÃO EM LABORATÓRIO: DESAFIOS E FRUSTRAÇÕES DE UMA EXPERIÊNCIA \\ DOI: http://dx.doi.org/10.5007/1983-4535.2012v5n3p287}

das ciências naturais para ensinar administração. Na perspectiva dos autores do projeto, o ensino-aprendizagem em administração deveria levar seriamente em consideração contribuições de pesquisa tais como as do projeto ETL (Enhancing Teaching-Learning Environments in Undergraduate Courses) de Hounsell e Entwistle (2005).

Segundo Hounsell e Entwistle, as pesquisas demonstraram que dois conceitos parecem ser facilitadores do aprendizado: a) os conceitos de entrada (threshold concepts) e os WTPs (Ways of Thinking and Practising in a Subject - Formas de Pensar e Praticar em uma Disciplina). Os conceitos de entrada são "portais, abrindo novas formas de pensar antes inacessíveis [constituindo] uma forma de compreender algo sem a qual o aluno não consegue prosseguir. [Para atingir este estágio, o estudante deve]... deixar para trás posições confortáveis de pensamento e explorar posições desconcertantes" (p.5).

Um dos principais objetivos do projeto LPO foi construir um tipo de ambiente de aprendizagem que possibilitasse aos participantes captar o sentido do que seja fazer parte de uma organização de trabalho. Neste artigo queremos apresentar uma reflexão sobre a experiência vivida. $\mathrm{O}$ relato da experiência começa com a descrição do contexto em que se insere o ensino de Administração. Em seguida, descreveremos as expectativas e as premissas conceituais do projeto, para logo a seguir explicarmos como ele foi construído e executado na prática. Na parte final, refletimos sobre alguns desafios que enfrentamos na execução da proposta e algumas frustrações que tivemos. Encerraremos o trabalho apresentando algumas conclusões parciais. Cabe ressaltar que, em função do nosso interesse e envolvimento com o projeto, não pretendemos escapar da subjetividade de nosso relato e, portanto, descrevemos nossa experiência na primeira pessoa do plural. Como será percebido em nossa descrição, investimos nesta experiência não apenas tempo e intelecto, mas, principalmente, capital emocional.

\section{O CONTEXTO DO ENSINO-APRENDIZAGEM EM ADMINISTRAÇÃO}

Antes de descrevermos a concepção e o oferecimento do projeto LPO, gostaríamos de contextualizar a nossa preocupação com relação ao processo de ensino-aprendizagem em Administração e defender a necessidade de mudanças. $\mathrm{O}$ termo ensino e aprendizagem em Administração é utilizado aqui de forma inapropriada, pois o que queremos dizer com ele engloba, na verdade, um conjunto de conhecimentos, habilidades e técnicas em diversas áreas. Na verdade, não há como estabelecer um rol destes conhecimentos, habilidades e 


\section{APRENDENDO ADMINISTRAÇÃO EM LABORATÓRIO: DESAFIOS E FRUSTRAÇÕES DE UMA EXPERIÊNCIA \\ DOI: http://dx.doi.org/10.5007/1983-4535.2012v5n3p287}

técnicas. No entanto, de uma forma geral, isto engloba todos aqueles fatores que fariam uma pessoa se sentir competente e confiante de exercer um papel administrativo ou gerencial em uma organização. No entanto, por estarmos - os dois autores - localizados em um departamento universitário denominado "Administração e Contabilidade", adotaremos o termo administração como síntese deste conjunto de "competências" que se espera de alguém que se prepare para ocupar um papel no cenário das organizações.

Segundo o relatório Global Focus (2008), devido a diversos fatores, entre eles as contínuas iniciativas de expansão do ensino superior, há clara evidência de que a demanda pelo ensino de administração, e consequentemente de conhecimentos correlatos, continuará a crescer. No entanto, McGregor (2004) aponta que

Em um mundo caracterizado por mudança, diversidade e complexidade, com as instituições de ensino, como outras, aspirando se tornarem "organizações que aprendem" e onde a "economia do conhecimento" é aparentemente crucial, as escolas como espaço de aprendizado parecem continuar estáticas. A maioria exibe arranjos físicos, organizacionais e sociais que mudaram relativamente pouco nos últimos 150 anos (p.13).

Isto também é verdade para a maioria das escolas de administração no Brasil, que repetem basicamente a mesma organização e metodologia de ensino herdada da tradição norte-americana que serviu de base para a introdução de nossos cursos de administração. Este tipo de metodologia, que aqui chamaremos tradicional, é dominante no processo educacional, não apenas no curso de administração, mas na maioria dos cursos superiores, sejam eles profissionais ou não.

Outra característica inadequada da prática pedagógica tradicional é a crença na especialização do conhecimento e na sua transmissão através de disciplinas específicas. No ensino de administração, isto se configura através de uma exagerada ênfase dada ao ensino das quatro funções consideradas básicas na administração, ou seja, produção, marketing, finanças e recursos humanos. No entanto, a literatura pedagógica já reconhece que a capacitação do trabalhador para desempenhar atividades na sociedade atual não pode ser disponibilizada por disciplinas isoladas nem feita de forma sequencial e acumulativa. Segundo Morin (2000), "as mentes formadas pelas disciplinas perdem suas aptidões naturais para contextualizar os saberes, do mesmo modo que para integrá-los em seus conjuntos naturais" (p.40). 


\section{APRENDENDO ADMINISTRAÇÃO EM LABORATÓRIO: DESAFIOS E FRUSTRAÇÕES DE UMA EXPERIÊNCIA \\ DOI: http://dx.doi.org/10.5007/1983-4535.2012v5n3p287}

Ao mesmo tempo, Domingues (2001) observa que se, por um lado, houve uma "crescente e impactante superespecialização do conhecimento, gerando uma infinidade de disciplinas e especialidades" (p. 7), por outro lado, isto tem gerado tentativas de reaproximação dessas mesmas diferentes disciplinas e especialidades. No entanto, se formos observar em detalhes a operacionalização destas tentativas de reaproximação, constataremos que a estrutura física, a organização acadêmica e o sistema de incentivos nas instituições de ensino ainda dão pouca abertura às iniciativas de inter e transdisciplinaridade.

As tentativas de integração que partem das escolas de administração, na verdade, sofrem uma série de restrições. Por exemplo, Araújo e Farias (2007) descrevendo o desenvolvimento de um novo projeto pedagógico para os cursos de administração da Universidade Estadual de Pernambuco (UPE) afirmam que, a princípio, "foi possível abandonar os olhares disciplinares e avançar no sentido de pensar os fatos, as dimensões e o processo educacional em sua natural complexidade" (p.5 - grifo no original). No entanto, logo a seguir, os autores informam que, apesar da adequação aos objetivos, não foi viável "avançar para além da matriz disciplinar tradicional" (p.5), porque isto dificultaria eventuais transferências de alunos de e para o curso. Estas restrições observadas na tentativa de conciliar a estrutura tradicional curricular e formas inter ou transdisciplinares de ensino são congênitas e parecem intransponíveis. Tais tentativas ignoram o preceito de que uma estratégia deve ter sua própria estrutura e, portanto, que para se ter um ambiente mais naturalístico no ensino de administração é preciso que o ambiente conceitual e físico seja adaptado para este fim.

Para atingir esta congruência entre objetivo e ambiente na educação profissional, Schön (1987) advoga a construção de uma nova epistemologia da educação profissional, onde os atos pedagógicos acontecessem em um "laboratório reflexivo" (reflective practicum) no qual os estudantes aprendessem principalmente por meio do fazer reflexivo, ajudado por tutores experientes. Os "créditos" obtidos nestas atividades poderiam, então, ser aproveitados pelo currículo tradicional. São de nosso conhecimento dois modelos que, embora de forma tímida, se aproximam destas características: o modelo SENAC de escritório modelo e o modelo Europen-SEBRAE de empresas simuladas. Por falta de espaço não vamos descrever estes modelos, mas aqueles interessados podem obter informações sobre o modelo EuropenSEBRAE de empresas simuladas em www.europen.de. Para conferir as vantagens e 


\section{APRENDENDO ADMINISTRAÇÃO EM LABORATÓRIO: DESAFIOS E FRUSTRAÇÕES DE UMA EXPERIÊNCIA \\ DOI: http://dx.doi.org/10.5007/1983-4535.2012v5n3p287}

desvantagens deste modelo vide Gramlinger (2004) e para uma visão fenomenográfica do mesmo consulte Santos (2008).

\section{AS PREMISSAS DA PROPOSTA CONCEITUAL DO LPO}

O conceito de "ambientes laboratoriais" onde o estudante interage com seu objeto de estudo é comum no ensino de ciências naturais de todas as Universidades, inclusive a nossa. No entanto, o conceito de "ambiente laboratorial" também tem crescido no campo das ciências sociais. Na nossa universidade, por exemplo, há ambientes laboratoriais nos cursos de Comunicação, Direito e Economia Doméstica. Um ambiente deste tipo, a nosso ver, poderia também ser viável e útil ao Departamento de Administração e Contabilidade. Mas, ao mesmo tempo, não queríamos um ambiente laboratorial no sentido proposto por Oliveira (2009), que baseado nos trabalhos de Sauaia (2008), propõe um ambiente onde são aplicados exercícios de gestão simulados (jogos de empresas).

Desta forma, nossa base conceitual para a proposta do LPO se assentou na visão construtivista de aprendizado. Esta perspectiva de aprendizado pressupõe que a constituição de "conteúdo significativo" para o aprendiz é o principal produto da atividade de aprendizagem. Para permitir esta transformação nós críamos na necessidade de atender a duas premissas básicas. Em primeiro lugar, romper com a tradição da oralidade discursiva do professor presente em sala de aula, reservando a este um papel de organizador de experiências pedagógicas significativas ou de um treinador que catalisa "tanto o poder quanto o prazer da aprendizagem pela ação" (MARQUARDT, 2005, p. 142). Isto significaria transferir para o estudante grande parte da responsabilidade pela construção da realidade organizacional em que ele se inseriria e também de co-responsabilizá-lo pela construção de seu conhecimento e de sua identidade profissional. Um efeito colateral esperado desta nova configuração de papéis era enfatizar a função da comunicação no fenômeno organizacional, à medida que o participante percebesse a importância da função comunicação na construção desta realidade.

Em segundo lugar, nós críamos que as atividades realizadas pelos participantes no projeto devessem ter uma semelhança bem próxima ao "real"; realidade aqui entendida como o que acontece na sociedade mais ampla. Alguns processos sociais importantes são, por exemplo: como se dá a divisão de trabalho, como se opera a coordenação de atividades, como se exercem os controles, etc. Mas realidade também entendida como realidade reduzida, no sentido de que sua complexidade fosse construída em camadas, sendo cada camada um passo 
para camadas superiores de entendimento do fenômeno organização. Ao mesmo tempo, pretendíamos que as reduções necessárias para possibilitar o entendimento desta realidade não esmaecessem a necessidade de o estudante se comportar desde o início como um aprendiz inserindo-se em uma específica comunidade de prática (WENGER, 1998).

Foi neste sentido que nós propusemos no nosso modelo o conceito de mundo paralelo ou país paralelo. Por "mundo paralelo ou país paralelo" queríamos dizer que o LPO deveria introduzir um mundo que fosse próprio de seus participantes, no sentido de que ele conteria suas próprias normas e seus procedimentos característicos; não no sentido de diferente e alheio ao restante da realidade, mas no sentido de anexo, similar e reduzido. A preocupação aqui era criar um espaço conceitual onde o mundo real fosse reduzido e adaptado para um propósito pedagógico. Neste espaço reduzido e adaptado, prevíamos a possibilidade de uma liberdade de formas de associação, onde não apenas empresas fossem idealizadas, mas também outros tipos de organizações sociais tais como cooperativas e entidades civis. Este mundo paralelo foi chamado no modelo de República Pedagógica de Simulândia.

\section{CONSTRUINDO E EXECUTANDO A PROPOSTA}

A construção do modelo começou a ser concretizada com a apresentação de um projeto de pesquisa para a FAPEMIG em dezembro de 2008. Além disto, participamos de outras propostas de incentivo à pesquisa da própria instituição de que fazemos parte para conseguirmos outros bolsistas de iniciação científica. Dada à demora dos processos de financiamento, mesmo antes de aprovada a proposta, a equipe se organizou para preparar a dinâmica do oferecimento. A primeira questão prática que se apresentava era sob que forma oferecer a atividade. Duas alternativas foram consideradas: a) o oferecimento da atividade como um curso de extensão; ou b) o oferecimento da atividade como uma disciplina "optativa". Embora, conceitualmente, o oferecimento de uma atividade como curso de extensão fosse mais coerente, chegamos à conclusão que, devido principalmente à principal dificuldade que prevíamos - o espaço físico - o oferecimento através de uma disciplina optativa fosse a melhor alternativa de momento.

Outra tarefa preliminar foi criar a estrutura e a dinâmica das atividades as quais os estudantes estariam sujeitos. Isto exigiu a construção de um conjunto de regras - que chamamos de "leis de Simulândia". Este conjunto de leis e resoluções foi considerado o arcabouço jurídico de Simulândia e disponibilizado através de um site que serviu como ponto 


\section{APRENDENDO ADMINISTRAÇÃO EM LABORATÓRIO: DESAFIOS E FRUSTRAÇÕES DE UMA EXPERIÊNCIA \\ DOI: http://dx.doi.org/10.5007/1983-4535.2012v5n3p287}

de referência para os participantes. Todos os direitos e deveres dos cidadãos de Simulândia estavam contidos nestas leis. Ficou também estabelecido, conforme o parágrafo $1^{\mathrm{o}}$ do artigo $1^{\circ}$ da Constituição da República Pedagógica de Simulândia que, subsidiariamente, aplicar-seiam em Simulândia as leis e normas da República Federativa do Brasil. Foi criado o Conselho Pedagógico de Simulândia, representado pelos professores coordenadores do projeto, que representaria a instância máxima dos poderes executivos, legislativo e judiciário. Todas as leis e resoluções de Simulândia foram publicadas em um Diário Oficial de Simulândia. Foi criado o site do projeto onde Simulândia foi definido como: "um país imaginário que existe para que os estudantes [...] aprendam vivencialmente os princípios e técnicas necessários para a concepção, construção, funcionamento, desenvolvimento e controle de organizações sociais".

Simulândia foi concebido com dois segmentos distintos: o governo e a sociedade civil. O principal objetivo do governo era criar e operar a estrutura funcional do projeto. No governo, além dos professores coordenadores do projeto, estiveram cinco bolsistas financiados por quatro projetos institucionais distintos: (FAPEMIG, PIBIC, PIBIC-Junior e PIBEX). Este suporte foi essencial para a operacionalização do projeto.

Funcionalmente, o governo foi estruturado em cinco órgãos: o Banco Central, o Departamento de Fazenda, o Departamento de Registro Civil e Comercial, o Departamento de Planejamento e Controle e o Instituto de Qualidade e Produtividade. Estes órgãos executariam as funções de organização e controle conforme estabelecido na lei 002 de Simulândia. Assim, O Departamento de Registro Civil e Comercial ficou responsável pela emissão das carteiras de identidade de cada participante no projeto, como também pelo registro dos contratos sociais das empresas. O Banco Central exerceu a função de banco controlador da política monetária do governo de Simulândia, de banco comercial (empréstimos e controle de meios de pagamento) e de banco de desenvolvimento (fomento de atividades econômicas através de editais). Além disto, todas as transações financeiras deveriam ser feitas através do Banco Central.

O Departamento de Fazenda teve, entre outras, a função de emitir e controlar o Cadastro Nacional de Pessoas Jurídicas; administrar os tributos internos; autorizar a emissão de Notas Fiscais e executar a fiscalização e as auditorias. O Departamento de Planejamento e Controle ficou encarregado de executar os controles internos do governo tais como elaborar o orçamento do governo, publicar as leis, atos e resoluções e gerir o pessoal de governo. Finalmente, o Instituto de Qualidade e Produtividade foi desenhado para apoiar o 


\section{APRENDENDO ADMINISTRAÇÃO EM LABORATÓRIO: DESAFIOS E FRUSTRAÇÕES DE UMA EXPERIÊNCIA \\ DOI: http://dx.doi.org/10.5007/1983-4535.2012v5n3p287}

desenvolvimento da qualidade e produtividade tanto dos setores do governo quanto das empresas e outras organizações da sociedade civil, promover eventos para o desenvolvimento da qualidade e produtividade das organizações constituídas em Simulândia e realizar as auditorias internas de qualidade nos setores de governo de Simulândia, bem como as auditorias externas de qualidade nas diversas organizações constituídas em Simulândia.

A sociedade civil foi composta pelos estudantes matriculados na disciplina. Eles seriam os responsáveis pelo desenvolvimento e geração da riqueza do país Simulândia. Para tanto, eles deveriam conceber, constituir e operar organizações sociais (empresas, cooperativas, associações, etc.) com objetivos sociais definidos e de acordo com as leis de Simulândia. Apesar de imaginário e pedagógico, Simulândia seria um país real no sentido de que ofereceria produtos e serviços reais a seus cidadãos, uma diferença considerada essencial em relação aos modelos SENAC e Europen/SEBRAE.

Em função de diversas restrições e limitações que vão ser discutidas a seguir, percebíamos que o projeto iniciar-se-ia com uma grande lacuna entre o desejado e o possível. Como exemplo desta lacuna, achávamos que a decisão de oferecer a atividade através de uma "disciplina curricular" de 60 horas nos permitiria reunir a turma apenas duas vezes por semana, o que era considerado muito pouco e irreal. No entanto, nós críamos que o projeto já apresentava uma coluna dorsal e uma proposta concreta de trabalho e, por isso, resolvemos ir em frente. Na turma 1, por exemplo, cerca de 45 estudantes dos cursos de Administração, Contabilidade e Engenharia de Produção matricularam-se na disciplina. Os matriculados se dividiram em cinco grupos (empresas) de Simulândia. As empresas se concentraram principalmente em atividades comerciais, como foi o caso de uma empresa que comercializou bombons. Esta característica limitou o leque de experiências a que o grupo se expos.

Com a experiência e as dificuldades encontradas com a turma 1, foram introduzidas diversas modificações na turma 2 . Na turma 2 , limitamos o número de matriculados para vinte estudantes e atendemos apenas aos cursos de Administração e Contabilidade. O tipo de empreendimento que se poderia formar também foi ajustado, introduzindo-se o que denominamos demanda induzida. Esta demanda foi criada atendendo a algumas necessidades de professores e de setores do próprio Departamento de Administração e Contabilidade que apontaram produtos e serviços que gostariam de consumir.

Introduzimos também um cronograma mais detalhado com uma série de atividades e datas limites para a apresentação de resultados. Além disto, os primeiros encontros na 
disciplina foram utilizados para inserir os participantes na lógica do projeto. Explicamos os diversos requisitos do projeto, insistimos na especificidade da "disciplina" e na diferença desta em relação a outras disciplinas de cunho essencialmente teórico. Para ressaltar esta especificidade, salientamos que a avaliação seria feita através de auditorias contábeisfinanceiras e auditorias de qualidade e não através de provas e exercícios. Nesta fase, houveram algumas palestras ministradas por especialistas do departamento sobre plano de negócio, abertura de empresas e controle de qualidade. Com este treinamento inicial, esperávamos ajustar o comportamento esperado dos participantes. Após estes encontros, os grupos foram deixados livres para poderem se organizar e começar a produzir.

\section{REFLETINDO SOBRE A EXPERIÊNCIA}

Antes de relatarmos os desafios e frustrações com o projeto, queremos chamar a atenção para a natureza complexa e difusa do fenômeno ensino-aprendizagem em administração. Não sabemos ainda muito bem o que faz uma pessoa aprender ou ser considerada eficaz neste campo, particularmente quando por aprendizado queremos dizer não apenas a internalização de conhecimentos ou a expressão de habilidades desconectadas de sua utilização. Como observam Bereiter e Scardamalia (2003) "só nas habilidades básicas de ler, escrever e de usar a matemática elementar nós sabemos como ensinar... com a confiança de que elas se transferirão para uma larga escala de situações” (p.55). Na grande maioria de outros processos educacionais e especialmente em administração, os resultados são incertos e dependentes de uma série de fatores que os educadores ou ainda não conhecem muito bem ou não podem controlar.

Assim, gostaríamos de expor nossa reflexão sobre a experiência que tivemos sob a forma de um conjunto de desafios e de frustrações. Não queremos afirmar que desafios e frustrações sejam conceitos opostos, nem considerá-los de forma estanque. Ao enfrentar desafios podemos vencê-los ou não; se os vencemos constituem-se em vitórias, se não os vencemos se tornam frustrações. Mas temos plena consciência de que vitórias ou frustrações são momentos passageiros. O nosso relato da experiência nestas duas categorias, portanto, é mais um recurso de estilo do que uma concepção de realidade. 


\subsection{DESAFIOS}

Todo projeto inovador encontra desafios. Não foi diferente com o nosso. Bilimoria (1998) desdobra os desafios da aprendizagem experiencial em pedagógicos e institucionais e levanta uma série de questões. Algumas delas são: qual o papel do professor neste processo? Que teorias e materiais são necessários para facilitar a aprendizagem experiencial? Como deve ser feita a avaliação do processo? Que ajustes precisam ser feitos nos sistemas de recompensa dos professores para que seja levado em consideração o aumento de tempo e energia necessários para a prática da aprendizagem experiencial? Estes e outros desafios existiram (e continuam a existir) no nosso projeto. No entanto, existem três desafios que gostaríamos de comentar com mais detalhes neste trabalho. Eles são os seguintes:

- A Batalha pela Construção da Legitimidade do Projeto;

- A Busca do Envolvimento de Outros Parceiros;

- A Necessidade de Compreensão da Atitude dos Estudantes.

\subsubsection{A batalha pela construção da legitimidade do projeto}

Um dos desafios do projeto foi o que poderíamos chamar de construção de sua legitimidade. Este tipo de desafio não é específico ao nosso projeto, mas uma condição imposta pelo paradigma dominante a todo procedimento inovador. $\mathrm{O}$ desafio se constitui em uma série de protocolos formais de apresentação do projeto a canais de decisão para esclarecimentos e convencimentos da sua viabilidade. No nosso caso, isto significou uma série de conversas com colegas professores, com o chefe de departamento e outras instâncias superiores e, finalmente, a redação de uma proposta que foi encaminhada ao colegiado do departamento para deliberação. Após a aprovação em colegiado, a proposta teve diversos outros trâmites burocráticos até ser disponibilizada como disciplina aos estudantes.

Ao mesmo tempo em que foi preciso construir a legitimidade do projeto em relação à instituição, também foi preciso construir esta legitimidade em relação aos estudantes. Isto significou tornar o projeto conhecido e, concomitantemente, que ele fosse considerado uma atividade complementar relevante de aprendizado. Era preciso competir igualitariamente com as outras atividades que eram oferecidas aos estudantes para que eles completassem os "créditos" necessários para terminar o curso. Apenas o conhecimento da existência da atividade pelos estudantes não era um requisito suficiente para o reconhecimento do projeto, 


\section{APRENDENDO ADMINISTRAÇÃO EM LABORATÓRIO: DESAFIOS E FRUSTRAÇÕES DE UMA EXPERIÊNCIA \\ DOI: http://dx.doi.org/10.5007/1983-4535.2012v5n3p287}

pois eles precisavam também considerar que participar da atividade era melhor em comparação com outras opções disponíveis a eles.

Deve-se levar em consideração também que a construção da legitimidade não se encerra com o oferecimento inicial da atividade. Ela é um trabalho demorado e complexo cujo esforço foi apenas iniciado nos primeiros doze meses de projeto. O que notamos também foi que o retorno pelo esforço empregado na construção da legitimidade de um projeto costuma contrariar a lógica, surgindo de onde menos se espera. Por exemplo, a apresentação do projeto por um de nossos bolsistas em um evento científico despertou o interesse de uma instituição do terceiro setor para se estabelecer uma parceria com o objetivo de atender um público externo à Universidade.

\subsubsection{A busca de envolvimento de outros parceiros}

Outro desafio encontrado no projeto foi a incessante busca de envolvimento de outros professores e parceiros. Ficamos com a percepção que um modelo de aprendizagem experiencial é bem vindo ao processo de aprendizagem organizacional por outros professores, pois, em nossa experiência, não encontramos resistências explícitas ao nosso propósito de ensino. Embora o entusiasmo tenha contagiado apenas os dois professores iniciadores da proposta, percebemos que os outros professores foram solícitos aos nossos pedidos de cooperação e que suas participações foram além do papel de meros professores. Por exemplo: o governo de Simulândia lançou um edital para a compra de prestação de serviços de criação e divulgação da marca e de slogan do projeto. O julgamento e a seleção das propostas foram realizados em sessão pública, baseados na lei brasileira de licitações. Solicitamos a cooperação de dois professores do departamento que seriam os analistas responsáveis pela avaliação técnica das propostas. Duas empresas apresentaram propostas, sendo uma posteriormente desclassificada por irregularidade na documentação. Os dois professores analisaram, então, a proposta técnica da empresa licitante, de acordo com os seguintes critérios previstos no edital: a) adequação ao objeto do edital; b) demonstração de capacidade de atender tecnicamente e em tempo hábil o projeto proposto; c) conformidade do preço proposto aos preços de mercado; e d) criatividade.

Um dos professores analista convidados tinha grande experiência na área de compras baseadas na referida lei e analisou a proposta, mostrando à representante da empresa licitante, diversos ajustes tanto técnicos quanto comportamentais que deveriam ser levados em 


\section{APRENDENDO ADMINISTRAÇÃO EM LABORATÓRIO: DESAFIOS E FRUSTRAÇÕES DE UMA EXPERIÊNCIA \\ DOI: http://dx.doi.org/10.5007/1983-4535.2012v5n3p287}

consideração na apresentação de uma proposta a um edital público. Creio que a experiência foi rica e valiosa para todos os presentes, pois foram demonstrados em uma situação realística os diversos elementos constitutivos de uma licitação pública.

Mas notamos também que existe um conflito sutil entre a participação em atividades desta natureza e outras que são mais valorizadas academicamente. Os professores estão constantemente em busca de reconhecimento acadêmico e progressão na carreira, o que faz com que atividades tais como pesquisas, publicações científicas e programas de treinamento sejam mais valorizadas, pois estas trazem maior reconhecimento entre os pares e melhor remuneração pessoal. Como diz Silva (2006, apud MAFRA et al, 2009), “ o sistema de ensino se estrutura em função de uma idéia produtivista que envolve docente e discente numa obsessiva [e também dissimulada] competição: é preciso apresentar resultados” (p. 13)

\subsubsection{A necessidade de compreensão da atitude dos estudantes}

Outra fonte de desafios no nosso projeto foi a necessidade de compreendermos a complexidade da atitude dos estudantes, tanto enquanto indivíduos isolados quanto como participantes de um grupo definido. Segundo Askew e Carnell (1998), os estudantes vêm para a sala de aula com pré-concepções sobre como o mundo funciona. Isto inclui, naturalmente, pré-concepções sobre como a escola funciona. Toda vez que se reúnem em uma sala da aula, estudantes acostumados a um sistema tradicional de ensino-aprendizagem esperam encontrar: um professor, que este professor conduza as atividades, que exista um conteúdo a dominar, que este conteúdo seja o alvo da avaliação, etc. Quebrar estas expectativas iniciais requer determinação.

A mudança destes pressupostos dos estudantes no projeto não foi apenas desafiadora, mas muitas vezes conflitante, porque uma atividade diferente em meio a tantas outras atividades que são vistas, obviamente, como pertencentes à rotina de uma escola é tida como destoante. Nosso projeto tinha diversas características do paradigma tradicional. Por exemplo, era uma "disciplina optativa" e tinha de registrar uma avaliação individual em forma de nota de 0 a 100 ao final do semestre. Isto fazia nosso discurso explícito ou implícito soar, em diversos momentos, como falso. Um dos exemplos que podemos citar foi o momento da avaliação da turma 1. Como não tínhamos pensado um sistema de avaliação que refletisse o desempenho individual, decidimos dar uma avaliação igual a 90\% dos pontos para todos os participantes. No entanto, recebemos uma reclamação indignada de uma das participantes - 


\section{APRENDENDO ADMINISTRAÇÃO EM LABORATÓRIO: DESAFIOS E FRUSTRAÇÕES DE UMA EXPERIÊNCIA \\ DOI: http://dx.doi.org/10.5007/1983-4535.2012v5n3p287}

que tinha tido uma participação destacada no projeto - que achou injusto ser comparada igualitariamente com os demais. Isto nos fez perceber a complexidade de entender o indivíduo tanto enquanto um ser isolado como também como um membro de um grupo.

Segundo nossas observações, percebemos grupos que trabalharam muito bem como equipe, outros que trabalharam regularmente bem e outros que foram verdadeiros desastres. Houve inclusive um caso em que o estudante preferiu trabalhar sozinho, constituindo uma empresa individual. $\mathrm{O}$ fato de termos tido grupos com atitudes e desempenhos tão diferentes aflora diversas questões. O que provocou estas diferenças em termos de atitudes e desempenho? E o que estas diferenças nos dizem sobre o como estamos lidando com grupos no processo de ensino-aprendizagem? São questões que ficaram em aberto. O que conseguimos captar na nossa experiência em Simulândia foi a importância do conceito grupo e a amplitude de nossa ignorância e incapacidade quando se trata de utilizar o conhecimento já gerado pela teoria de grupos no processo educacional (BOOT E REYNOLDS, 1997).

\subsection{FRUSTRAÇÕES}

Ao mesmo tempo em que enfrentávamos os desafios, colecionávamos também algumas frustrações. As frustrações na implantação e na operacionalização do projeto podem ser sintetizadas na expressão de, após um ano de trabalho, termos ficado com a clara sensação de que "não era bem isto o que queríamos". Clark e Peterson (1986, apud BISSEL, 2004), por exemplo, aponta que "restrições ao comportamento do professor emanadas do conteúdo do curriculum obrigatório, recursos e tempo disponíveis, hábitos e habilidades dos estudantes podem se interpor entre a teoria e a ação e ser responsável [por] discrepâncias observadas entre as crenças e as práticas do professor” (p. 28). Esta discrepância entre crença e práticas gerou, no nosso caso, uma série de frustrações que, por falta de espaço, gostaríamos de sintetizar, explorando apenas dois itens específicos:

- A Inevitabilidade de Dissonância entre Teoria e Prática na Academia;

- A Não Obtenção de uma Estrutura Física Adequada para o Projeto.

\subsubsection{A inevitabilidade de dissonância entre teoria e prática na academia}

Simon (1964) e Schön (1983) alertam para a dificuldade de integração entre teoria e prática nas escolas profissionais quando estas estão localizadas em Universidades. Neste ambiente, as escolas profissionais, entre elas a Administração, precisam resolver os conflitos 


\section{APRENDENDO ADMINISTRAÇÃO EM LABORATÓRIO: DESAFIOS E FRUSTRAÇÕES DE UMA EXPERIÊNCIA \\ DOI: http://dx.doi.org/10.5007/1983-4535.2012v5n3p287}

entre uma orientação acadêmica (relacionada aos cânones de uma determinada disciplina) e uma orientação prática (relacionada à resolução de problemas, geralmente, trazidos por ou originados em elementos externos ao programa do curso). Isto resulta em tensões, por exemplo, entre aqueles que consideram e querem ver o campo de estudo em questão como uma ciência (mesmo que seja uma ciência aplicada) e aqueles que o consideram como sendo uma arte; entre aqueles que preferem a análise e aqueles que privilegiam a síntese; e entre aqueles que estão em busca de explicações (geralmente na forma de relações de causa-efeito) e aqueles que querem ver um plano de ação. Simon (1964) alerta: "o objetivo do cientista é explicar o fenômeno na natureza... o objetivo do sujeito prático é configurar ações, processos ou estruturas que funcionem - que sirvam a um propósito específico” (p. 212).

Estes conflitos, acreditamos, não passam despercebidos aos estudantes, que mesmo não os assimilando racionalmente, são afetados subjetivamente por eles. Um exemplo destes conflitos ficou explícito em Simulândia com suas "leis" que buscavam refletir a realidade, ao mesmo tempo em que a estrutura formal da atividade era de uma "disciplina", com seu conteúdo implícito e a necessidade de se obter uma nota de aprovação. O que está valendo? O discurso do professor ou a realidade que o contradiz? A nosso ver, no final, a realidade prevaleceu.

Esta dissonância entre teoria e prática encontra-se incorporada nas entranhas do meio acadêmico. Não há dúvida que a capacidade cognitiva dos estudantes é ativada quando expostos a uma aula expositiva tradicional; nem nos recusamos a acreditar que a memória tenha um papel importante a desempenhar no processo de aprendizado. Mas como afirma enfaticamente Drucker (1984), administrar é "uma aplicação, não conhecimento" (p. XXVI). Saber que um aluno é capaz de recitar os passos do processo racional de tomada de decisão não o faz, necessariamente, um tomador de decisões melhor. Além do mais, esta dissonância está presente no próprio corpo docente. Casos emblemáticos são: professores de planejamento que não se importam com o planejamento de seus cursos e de suas aulas ou professores de recursos humanos que não se importam em desenhar um processo de avaliação de desempenho de seus assistentes de pesquisa mesmo que minimamente; e muitos outros. Diante de tantos fatos que contradizem a teoria, o que se esperar que os estudantes aprendam?

Um dos autores lembra-se de, por exemplo, há algum tempo, estar ao lado de uma estudante de final de curso em uma palestra de um consultor externo, que ao ouvir mencionada a palavra duplicata perguntou a colega do lado: o que é isto? Naquele ponto do 


\section{APRENDENDO ADMINISTRAÇÃO EM LABORATÓRIO: DESAFIOS E FRUSTRAÇÕES DE UMA EXPERIÊNCIA \\ DOI: http://dx.doi.org/10.5007/1983-4535.2012v5n3p287}

curso, ela não sabia o que era uma duplicata! A realidade é esta: muitos estudantes saem do curso sabendo criticar a legislação social, sabendo discordar da carga de impostos que incide sobre uma empresa ou mesmo blasfemando contra a taxa de juros. Poucos, muitos poucos, no entanto, saberiam fazer uma folha de pagamento, calcular o imposto devido em uma transação ou comparar taxas de juros de operações financeiras reais. Os puristas do ensino tradicional diriam que os graduandos administradores ao saírem da Universidade não precisam saber fazer estas coisas pois apenas vão supervisionar o trabalho daqueles que irão fazer. Mas, é possível confiar em quem diz saber que não está bem feito um trabalho que não sabe fazer? A maioria dos empregadores diria que não.

A nossa frustração com relação a estes aspectos na experiência do projeto Simulândia é que apenas "arranhamos" estas questões. Também apenas arranhamos questões importantes relacionadas às relações interpessoais, ao processo de tomada de decisão e ao gerenciamento de conflitos. Preocupados com uma série de outras questões mais básicas e burocráticas, não tivemos tempo de aprofundar nestes pontos. Realmente não sabemos se aconteceu ou como aconteceu a integração entre teoria e prática. Apesar da opinião de alguns alunos com quem conversamos ser de que a experiência foi válida, não conseguimos ainda processar o real sentido desta validade. O que nos passou o discurso ouvido de alguns deles foi que esta validade teve mais a ver com a novidade da experiência do que com a profundidade do que foi aprendido. Definitivamente, não era isto o que queríamos.

\subsubsection{A não obtenção de uma estrutura física adequada para o projeto}

A segunda frustração que gostaríamos de comentar diz respeito à não obtenção de uma estrutura física que acomodasse o projeto. Embora o projeto tenha recebido apoio financeiro através da FAPEMIG e apoio implícito de todas as pessoas com quem mantivemos contato, os efeitos de nossos esforços pareciam esbarrar em uma restrição contextual prática bem concreta. Esta restrição contextual prática dizia respeito a falta de espaço físico que fosse dedicado especificamente para o projeto. Em certo sentido, podemos afirmar que não tínhamos, no início do projeto, a clara visão da importância do espaço para o sucesso do projeto. No nosso entender, falta de espaço dedicado para o projeto não foi apenas mais uma restrição ao projeto. Foi a restrição do projeto. A não obtenção de espaço dedicado ao projeto não foi falta de esforço de nossa parte, pois mantivemos contatos com diversas pessoas de diversos níveis hierárquicos na Universidade, dentro e fora do nosso departamento. No 


\section{APRENDENDO ADMINISTRAÇÃO EM LABORATÓRIO: DESAFIOS E FRUSTRAÇÕES DE UMA EXPERIÊNCIA \\ DOI: http://dx.doi.org/10.5007/1983-4535.2012v5n3p287}

entanto, espaço físico parecia ser naquele momento um recurso crítico na Universidade como um todo. Para consegui-lo era preciso ter mais peso político do que tínhamos no momento.

Neste sentido, nossa experiência corroborou o argumento de McGregor (2004) de que espaço faz diferença. Como afirma a autora, "espaço esconde coisas de nós, se deixamos de entendê-lo como sendo algo construído e contestável" (p. 13). E continua: "o silêncio que circunda o espaço permite que ele seja construído para produzir e reproduzir práticas que mantêm relações de poder assimétricas e persistentes" (p. 13). No nosso entender, Simulândia emitiu silenciosos sinais dúbios ao utilizar um espaço tradicional - a sala de aula - para oferecer uma proposta diferente de trabalho. A literatura reconhece que "professores que têm uma concepção mais complexa de seu trabalho (professores não-tradicionais) são freqüentemente incapazes de entender, experimentar ou implementar todos os aspectos desejados de seu trabalho devido a diversos fatores" (BISSEL, 2004, p. 28), entre eles fatores arquitetônicos.

\section{CONCLUSÕES PROVISÓRIAS}

É difícil falar em conclusões de uma experiência que apenas se iniciou. O que podemos frisar é que todas as conclusões que iremos relatar aqui de nossas experiências são definitivamente parciais. É preciso considerar também que nos envolvemos no projeto sob diversas perspectivas: como professores e como pesquisadores; como avaliadores das atividades realizadas pelas empresas e como clientes destas mesmas empresas; como agentes de controle na função de funcionários de governo de Simulândia e como meros expectadores do desenvolvimento das equipes. Nossa percepção do que se passou, portanto, é múltipla mas incompleta; diversificada mas fragmentada. Mas mesmo assim, gostaríamos de oferecer uma singela síntese de nossas percepções.

Em primeiro lugar, o que a breve experiência de Simulândia nos mostrou é que a abrangência de nossa "zona de ignorância" é bem maior do que imaginamos, mas que é possível avançarmos rapidamente para diminuirmos esta "falha geológica" entre o que pensamos que sabemos e o que é realmente relevante para o ensino-aprendizagem em administração. Poderíamos, talvez, começar por pesquisas que vasculhassem e aflorassem aquilo que Hounsell et al (2005) denominaram de "os conceitos de entrada" e os "WTPs" neste campo de aprendizagem. No aprimoramento do modelo de Simulândia, por exemplo, 


\section{APRENDENDO ADMINISTRAÇÃO EM LABORATÓRIO: DESAFIOS E FRUSTRAÇÕES DE UMA EXPERIÊNCIA \\ DOI: http://dx.doi.org/10.5007/1983-4535.2012v5n3p287}

pesquisas desta natureza poderiam ser trabalhos possíveis e importantes para podermos entender melhor o que significa ensinar e aprender administração.

Outra importante lição tirada de nossa experiência em Simulândia é a importância do papel da motivação do aprendiz para o aprendizado. O conceito de motivação deve ser entendido aqui não como um mercado de incentivos, um toma-lá-dá-cá, um escambo de tarefa por nota como é comum no ensino tradicional, mas como uma chama interior, um desejo de se inserir, de fazer parte, de se jogar na experiência. Isto, com certeza, não é nenhuma novidade na literatura sobre ensino-aprendizagem, mas fica evidente em ambientes de aprendizagem centrados no estudante. No entanto, para que esta motivação aconteça é preciso que o estudante perceba uma congruência entre o "curriculum oculto", ou seja, "todas as crenças, valores e entendimentos que são passados aos estudantes, não através do curriculum formal mas, inconscientemente, através das demandas implícitas feitas ao estudante pela instituição" (ROWNTREE, 1981 apud OTTEWILL et al, 2005, p.90) e as atividades do ambiente de aprendizagem. Junte-se a isto o que Parlett (1977) chama de "learning milieu", ou seja, os traços específicos da cultura onde se inserem os docentes e discentes; por exemplo, as crenças dos professores e as demandas veladas do Departamento. O que nos pareceu evidente na experiência em Simulândia é que os estudantes foram tão afetados por estas demandas implícitas e pelos elementos culturais de nosso departamento quanto pelas solicitações expressas emanadas por nós, "professores” responsáveis pelo projeto.

Temos fé que, apesar das frustrações, - sejam elas concretas, ou fruto, quem sabe, apenas de nossa incapacidade de superar os desafios apresentados - um ensino-aprendizagem baseado nas premissas de um "laboratório reflexivo" possa melhorar as condições de oferta do ensino-aprendizagem em administração. Baseados nesta esperança, pretendemos continuar a desenvolver o projeto Simulândia, assim que um espaço adequado esteja disponível. Em longo prazo, acreditamos na inevitabilidade da construção de uma epistemologia bastante diferente da que se disponibiliza hoje para o ensino-aprendizagem em administração. Uma epistemologia que reconheça que a consolidação de um campo de conhecimento ou prática tão importante para o mundo organizado deve postular, necessariamente, pelo menos dois argumentos básicos: a) que o que é único e admirável não seja tratado de forma tão banal e, b) que rigor e relevância dialoguem e não que disputem uma primazia no processo de aprendizagem. 
Finalmente, temos consciência de que muitas de nossas crenças expressas neste trabalho são apenas hipóteses, conjecturas que precisam de investigações mais profundas que as validem ou refutem. Como afirma Popper $(1945 ; 2010)$ apenas através da crítica apurada de nossos pressupostos podemos fazer avançar o nosso conhecimento do mundo.

\section{REFERÊNCIAS}

ARAÚJO, F. R. De Souza; FARIAS, O. B. R. de. Proposta de um Novo Modelo Pedagógico para o Curso de Graduação em Administração: uma discussão à luz da interdisciplinaridade. Anais do I Encontro de Ensino e Pesquisa em Administração e Contabilidade. Recife, PE: ANPAD, 2007.

ASKEW, Sue; CARNELL, Eileen. Transforming Learning: individual and global change. London, Washington: Cassell, 1998.

BARAB, S.; SQUIRE, K. Design-Based Research: putting a stake in the ground. The Journal of the Learning Sciences, 13(1), 1-14, Lawrence Erlbaum Associates, 2004.

BEREITER, C.; SCARDAMALIA, M. Learning to Work Creatively with Knowledge. Powerful Learning Environments: Unravelling Basic Components and Dimensions. E. Corte, L. Verschaffel, N. Entwistle and J. Merrienboer. Amsterdam, Pergamon, 2003.

BILIMORIA, D. The Editor's Corner. Journal of Management Education, Vol. 22 No. 3, June, 265-268, 1998.

BISSEL, J. Teachers' Construction of Space and Place: the method in the madness._Editorial. Forum. Volume 46, no. 1, 2004. Acesso pelo endereço http://www.wwwords.co.uk/forum/content/pdfs/46/issue46_1.asp em 17 de dezembro de 2010 .

BOOT, R.; REYNOLDS, M. Groups, Groupwork and Beyond. Management Learning: integrating perspectives in theory and practice. Sage Publications, London, 1997.

CLARK, C.; PETERSON, P. Teachers' Thought Processes. In M. Wittrock (Ed.) Handbook of Research on Teaching, Third Edition. New York: Macmillan, 1986.

COLLINS, A. Towards a Design Science of Education. In E. Scanlon \& T. O'Shea (eds.), New Directions in Educational Technology. New York: Springer-Verlag, 1992.

DOMINGUES, Ivan. (Ed.) Conhecimento e Transdisciplinaridade. Belo Horizonte, Editora UFMG, 2001.

DRUCKER, P. F. Introdução à Administração, São Paulo, Pioneira, 1984. 
GLOBAL FOCUS. Five Global Challenges in Management Education. http://findarticles.com/p/articles/mi_qa5475/is_200801/?tag=content;col1, 2008. Último acesso em 17 de dezembro de 2010.

GRAMLINGER, F. The Advantages and Disadvantages of Learning and Teaching in a Practice Firm. (Eds) New Approaches to Vocational Education in Europe: the construction of complex learning-teaching arrangements. Oxford Studies in Comparative Education 13(1): 81-90, 2004.

HOUNSELL, D.; ENTWISTLE N. et al. "Enhancing Teaching-Learning Environments in Undergradutate Courses." ETL Project - Final Report. http://www.ed.ac.uk/etl/. Último acesso em 01/05/2007, 2005.

ILLERIS, K. The Three Dimensions of Learning, Roskilde University Press, 2002.

MCGREGOR, Jane. Editorial. Forum. Volume 46, no. 1. Acesso pelo endereço http://www.wwwords.co.uk/forum/content/pdfs/46/issue46 1.asp, 2004. Último acesso em 17 de dezembro de 2010.

MAFRA, F. L. N. Ensino-Aprendizagem numa Perspectiva Crítica: relatos de um experiência. Anais do XXXIII Encontro da ANPAD, São Paulo, ANPAD, 2009.

MARQUARDT, M. J. O Poder da Aprendizagem pela Ação: como solucionar problemas e desenvolver líderes em tempo real. Rio de Janeiro, Editora Senac, 2005.

MASSEY, Doreen. Foreword. Forum. Volume 46, no. 1. 2004. Acesso pelo endereço http://www.wwwords.co.uk/forum/content/pdfs/46/issue46 1.asp,. Último acesso em $17 \mathrm{de}$ dezembro de 2010.

MORIN, E. Os Sete Saberes Necessários à Educação do Futuro. São Paulo, Cortez; Brasília, DF: UNESCO, 2001.

OTTEWILL, R. et al. Integration and the Hidden Curriculum in Business Education.

Education + Training, Vol. 47, no 2, pp. 89-97, 2005.

OLIVEIRA, M. A. Implantando o Laboratório de Gestão: um programa integrado de educação gerencial e pesquisa em Administração. Tese de Doutorado, Universidade de São Paulo, 2009.

PARLETT, M. The Department as a Learning Milieu. Studies in Higher Education, Vol. 2, No. 2, 173-181, 1977.

POPPER, K. R. Textos Escolhidos/Karl Popper. Rio de Janeiro, Contraponto, 2010.

ROWNTREE, D. A Dictionary of Education, Harper \& Row, London, 1981. 
SANTOS, J. A. dos. Students' Perceptions of the Practice Firms Network Learning Environment in Brazil: a phenomenographic approach. Lancaster, UK. University of Lancaster, Unpublished PhD Thesis, 2008.

SAUAIA, A. C. A. Laboratório de Gestão Empresarial: simulador, jogo de empresas e pesquisa aplicada. Barueri, SP: Manole, 2008.

SCHÖN, D. The Reflective Practitioner: How Professionals Think in Action. London, Aldershot, 1983.

SCHÖN, D. Educating the Reflective Practitioner: Toward a New Design for Teaching and Learning in the Professions. San Francisco, Jossey-Bass, 1987.

SILVA, A. O. da. A sua revista tem Qualis? Revista Espaço Acadêmico. N. 56, jan/2006, 2006.

WENGER, E. Communities of Practice: learning, meaning, and identity. Cambridge, U.K.; New York, N.Y, Cambridge University Press, 1998.

WILSON, B. What is a Constructivist Learning Environment? Constructivist Learning Environments: Case Studies in Instructional Design. B. Wilson. New Jersey, Educational Technology Publications, 1996.

WILSON, B. (Ed.) Constructivist Learning Environments: Case Studies in Instructional Design. Englewood Cliffs, N.J, Educational Technology Publications, 1996.

\footnotetext{
'Todas as traduções são de responsabilidade dos autores.
} 